\title{
Healthcare Workers' Perceptions Towards Hospital Leadership and Institutional Structure in Chiro and Gelemso Hospitals, West Hararghe Zone, East Ethiopia
}

\author{
Ayalew Aklilu, ${ }^{1, *}$, Shimels Hussien ${ }^{2}$, Kumlachew Abate ${ }^{3}$, Yonas Girma ${ }^{4}$, Shimeles Ololo \\ ${ }^{1}$ Tulane International, PCP/HMIS Unit, Addis Ababa, Ethiopia \\ ${ }^{2}$ World Health Organizations, Addis Ababa, Ethiopia \\ ${ }^{3}$ United Nations High Commission for Refugees, Juba, South Sudan \\ ${ }^{4}$ Center of International Reproductive Health Training (CIRHT), Bahir Dar University, Bahir Dar, Ethiopia \\ ${ }^{5}$ Jimma University, College of Public Health and Medical Sciences, Jimma, Ethiopia
}

\section{Email address:}

ayru_2010@yahoo.com (Ayalew A.),shimelsh@gmail.com (Shimels H.), abatekumlachew@gmail.com (Kumlachew A.), yonastile@gmail.com (Yonas G.), shimelessos@yahoo.com (Shimeles O.)

\section{To cite this article:}

Ayalew Aklilu, Shimels Hussien, Kumlachew Abate, Yonas Girma, Shimeles Ololo. Healthcare Workers' Perceptions Towards Hospital Leadership and Institutional Structure in Chiro and Gelemso Hospitals, West Hararghe Zone, East Ethiopia. Science Journal of Public Health . Vol. 3, No. 5, 2015, pp. 744-751. doi: 10.11648/j.sjph.20150305.31

\begin{abstract}
Background: Institutional structure, also called institutional formation is defined as the components and resources that an institution has to deliver its services and generate external support. Until recently, human resources have been overlooked during the course of health sector reforms. The perception of health worker towards institutional structure and leadership have an enormous impact for the successful implementation of health sector reform thus identifying factors that affect their perception have a significant importance for amending some of the organizational structure and advancing strategies to achieve organizational goals. And identifying factors that affect perception of health workers have eminent roles for mangers in order to improve and create a motivated health care provider. Objective: The objective of this study was to assess and determine factors that affect the perception of healthcare Workers towards the institutional structure and Leadership. Methods: A cross sectional quantitative survey was undertaken on 204 health workers from April 15 - 30, 2012. Self administered structured questionnaires were used to collect data. Data were entered and analyzed using SPSS Version 16. Multiple linear regressions were applied once after the assumptions checked. Result: This study showed that the overall perception of institutional structure and leadership is $37.2 \%$ and $31.6 \%$ respectively. About $59.3 \%$ of the respondents perceived that their Hospital did not give enough emphasis on the quality of service it provides and $69.6 \%$ of the health workers perceived that there were inadequate facilities. Educational status and place of work have shown association for the perception of health workers towards institutional structure while position was the only predictor for perception of health workers towards institutional leadership. Conclusion and Recommendation: Seeing the overall perception of health workers towards institutional structure and leadership was very low, promoting health workers based on their performance and strengthening Facilities infrastructure is decisive.
\end{abstract}

Keywords: Perception of Healthcare Worker, Leadership, Institutional Structure

\section{Introduction}

Institutional structure, also called institutional formation is defined as the components and resources that an institution has to deliver its services and generate external support. It is the embodiment of purpose of an institution. It is important because it should reflect and support the vision, mission, values, goals and strategy of the institution. It clearly defines and differentiates roles and functions in the institution, untangles lines of communication and accountability, and ensures that decision-making procedures are transparent and functional. The institutional structure is put in place to protect, support and enable the chosen vision, strategy and culture of the institution. The structure adopted in any institution will depend on the objectives of the institution, its environment and context, including technology and size (1). 
Until recently, human resources have been overlooked during the course of health sector reforms $(2,3)^{\circ}$ A number of factors ranging from the individual to national level operate together to influence how health workers take up interventions to improve their work practices. Often this influence works through the local, personal, educational, professional, community, or institutional environment in which work takes place or the social, cultural, economic, and political environments more generally (4).

Today, African health systems are experiencing one of the greatest staff shortages and clinical staff is currently faced weak institutional frameworks and distortive incentive structures, ineffective management practices and adverse work environments at systemic and organizational level, resulting in an overburdened health workforce (5).

During the past 15 years in sub-Saharan Africa, many countries have been undergoing health sector and civil service reforms that directly influence the design of the public health care system and the use of human resources (6). For more than a decade, Ethiopia has been implementing health sector reform which is now in its fourth phase of strategic planning but studies revealed that the ability of any institution attract, retain and maintain competent and satisfied staff into its employment is very challenging (7). And to strengthen this idea, the World development report 2004 state, without improvements to the human resources situation, the health-related Millennium Development Goals cannot be achieved (8).

A study conducted on 499 health workers in four Nigerian's hospitals revealed that about $64 \%$ of respondents disagreed or strongly disagreed that their hospitals had adequate staff in all key positions for health sector reform, $53 \%$ of the respondents disagreed or strongly disagreed that compensation were adequate for attracting, $57 \%$ of the respondents agreed or strongly agreed that opportunities exist for staff professional development and on-the-job training and keeping key staff, $69.9 \%$ perceived that there were inadequate facilities, and $39.5 \%$ line of reporting and authority are clear (1). Likewise, a study conducted in 551 health care workers of Ghana showed that $75 \%$ perceived lack of essential equipment, tools and supplies as a workplace issue affecting staff performance, and $94 \%$ perceived low salary as a workplace obstacle affecting staff performance (9). Another study in klang valley, Malysia showed that perception of health workers was influenced by age that older employees have favorable perception towards organizational culture. As well Jobs position, education and income also affect the perception of health workers (10).

On top of this, Good leadership is also important for the success of any organization. In a healthcare organization, good leadership is more than just important-it is absolutely critical to the organization's success (11). This may entail, as the issue of leadership determines worker perception towards their organization.

Most studies suggested that increasing salaries and benefits, better working and living conditions, management and supervision, career advancement and training and keeping staff healthy are significant to keep staff and to have favorable perception. $(12,13)$. And Employees desire to feel that they are a part of something substantial. When this occurs, employees find enthusiasm for their future and that of their organization. One method of achieving this is through a united vision where employees are empowered by their leaders to work toward the vision and within a value system that is congruent with their own (14).

However, what is happening in developing country is, contrary to this. There is poor level of health worker perception, which has a negative impact on the performance of individual health workers, facilities and the health system as a whole. Moreover, it adds to the push factors for migration of health workers, both from rural areas to the cities and out of the country $(12,13)$.

Healthcare worker perception and its influence on changing clinical practices of health workers in low-income settings was rarely explored as a major factor that may mediate or modify the effects of interventions (15). Furthermore, the area well not studied and no published studies found that clearly describes the level of health workers perception and its determinants, despite the fact that Ethiopia is among under developed country by which staff attrition is very high. Thus this study will serve for researcher as baseline information and for managers to be aware and take a decisive measure that help to build a satisfied and motivated healthcare worker.

The objective of this study was to assess and determine factors that affect the perception of healthcare workers towards the institutional structure and Leadership.

\section{Method}

\subsection{Study Area and Period}

Chiro and Gelmso Hospitals are located 320 and $372 \mathrm{~km}$ away from the capital Addis Ababa, west Hararghe zone, East Ethiopia. Facilities have 107 and 113 health workers respectively. The hospitals render services approximately $2,300,000$ population of the zone and are the only hospitals found in the zone.

The study was conducted on health workers served for more than 6 months, from April 15 - 30, 2012.

\subsection{Study Design, Sample, and Sampling}

A cross sectional quantitative survey was undertaken. The study was conducted among 204 health workers. The sample size was estimated based on single population proportion (p). The formula:

$$
n=\frac{(\mathrm{Z} \alpha / 2) 2 \mathrm{P}(1-\mathrm{P})}{(\mathrm{d}) 2}
$$

Since there were no local data available for the value of $P$ the sample size was estimated based on the assumption that $50 \%$ of health worker have good perception for organizational leadership and institutional structure with 5\% margin of error, and $95 \%$ confidence level, the required sample size $n$ had been 384 . As the sources population was $(<10,000)$ correction formula were used, 218 were a total number of Healthcare workers of the two hospitals in 2012. 
$\mathrm{nf}=\mathrm{n} /(1+\mathrm{n} / \mathrm{N}), \mathrm{N}=218, \mathrm{n}=384$

$=218 /(1+384 / 218)$

$=139+10 \%$ (non response rate) the total sample size was $=149$, but to increase the power of the study, it was conducted on all health workers who were eligible.

\subsection{Data Collection and Analysis}

Structured self administered questioner was used to collect data. The questionnaires had two parts. Part one had some closed-ended questions that help to assess socio-demographic characteristic and part two questions were answered on a 5point Likert scale i.e., $1=$ strongly disagree, $2=$ disagree, $3=$ undecided, $4=$ agree and $5=$ strongly agree . There were 26 items used to assess perception of health worker towards institutional structure and leadership. Among 26 item, 17 item were used to asses' institutional structure and the remaining for institutional leadership. These 26 items were measured on a 5-point likert scale for responses (Strongly disagree, Disagree, Undecided, Agree and strongly agree).

The collected data was checked for its completeness, and then cleaned, coded, edited, and entered, using SPSS version 16. For descriptive analysis Response strongly agrees and agrees had taken as positive response and responses undecided, disagree and strongly disagree considered as negative response. To explore factors that affect perception of health workers, the assigned weights " 1 " for strongly disagree to " 5 " for strongly agree were added together. Then by using the summated scale multiple linear regressions were used in order to identify the predictors for the outcome variable. Variables with p-value less than 0.05 had taken to fit the model.

\subsection{Operational Definition}

Leadership: the ability of administrative body of the two hospitals to influence, motivate, and enable others to contribute toward the effectiveness and success of the organizations of which they are members and have the following quality

- Communicates the vision or goal with employees

- Ability to create and maintain a culture of safety and quality throughout the hospital

- Makes space and equipment available as needed for the provision of care, treatment, and services

- Have a knowledge needed for their role

- helps an organization to be successful and create the future it wants

Health worker Perception: a process by which individuals organize and interpret their sensory impressions in order to give meaning to their environment and not necessarily based on reality, but is merely based on perspective of health worker towards

- Institutional structure and

- Leadership of Chiro and Gelemso hospitals'

Perception of Institutional structure: is defined as perception of health worker of Chiro or Gelemso towards

- Organizational climate
- Human resource

- and Infrastructure

Perception of Organizational climate: denotes perception of health workers of Chiro or Gelemso Hospitals whether the Hospitals are pleasant place to work, Values their employees, give enough emphasis on the quality of service it provides and open to their ideas.

Perception of Human resource: denotes perception of health workers of Chiro or Gelemso Hospitals whether the Hospitals have adequate staff, Compensation is fair, recruitment and hiring policy is clear and Staff are held accountable for getting work done according to clear performance standard.

Perception of Infrastructure: perception of health workers of Chiro or Gelemso Hospitals whether the Hospitals: have the needed technological resources, manage its technological resource effectively, have Adequate facilities and equipment and Facilities and equipment well maintained.

\subsection{Ethical Approval}

Ethical clearance was obtained from Ethical Review Board of Jimma University College of Public Health and Medical Sciences. Permission was also collected from both hospitals. Verbal Informed consent was taken from all study participants. Name of the study subjects remain anonymous or any identification had not written on questionnaire.

\section{Results}

\subsection{Basic Demographic of Respondents}

A total of 204 health workers agreed to participate in the study out of 218 , yielding a response rate of $93.6 \%$. About $84 \%$ of the respondents were between 21 and 30 years. The median age of the participants was 25 years with a range of 21 to 54 years. About $80 \%$ of the participants were less than six years service having 3 years of median services with a range of 2 to 25 years of services.

Table 1. Basic Demographic of health workers of Chiro and Gelemso hospitals, east Ethiopia, 2012.

\begin{tabular}{lll}
\hline Sex & Frequency $\mathbf{N = 2 0 4}$ & Percent \\
\hline Male & 103 & $50.5 \%$ \\
Female & 101 & $49.5 \%$ \\
Marital Status & & \\
Unmarried & 109 & 53.4 \\
Married & 95 & 46.6 \\
Religion & & \\
Muslim & 59 & 28.9 \\
Orthodox & 93 & 45.6 \\
Protestant & 34 & 16.7 \\
Catholic & 11 & 5.4 \\
Others & 7 & 3.4 \\
Ethnicity & & \\
Oromo & 92 & 45.1 \\
Amhara & 69 & 33.8 \\
Others & 43 & 21.1 \\
Hospital & & \\
Gelemso & 108 & 52.9 \\
Chiro & 96 & 47.1 \\
\hline
\end{tabular}




\begin{tabular}{lll}
\hline Sex & Frequency $\mathbf{N}=\mathbf{2 0 4}$ & Percent \\
\hline Profession & & \\
Physician & 15 & 7.4 \\
Nurse & 136 & 66.7 \\
Others & 53 & 26.0 \\
Position & & \\
Non Managerial & 177 & 86.8 \\
Managerial & 27 & 13.2 \\
Educational Status & & \\
Level IV/Diploma & 129 & 63.2 \\
BSC/Master & 75 & 36.8 \\
\hline
\end{tabular}

There were more males $(50.5 \%)$ than females which account $49.5 \%$. About $53 \%$ of the respondents were single and $45.1 \%$ of the respondents are Oromo whereas $45.6 \%$ are Orthodox. Just about $67 \%$ of the respondents were Nurses; Majority of the respondents $(52.9 \%)$ was from Gelemso hospital and 27 health workers had position in the hospital (Table 1).

\subsection{Perception of Health Workers Towards Institutional Structure and Leadership of Gelemso and Chiro Hospitals}

The percentage ratings of the healthcare workers' responses classified in to four dimensions as of three for Institutional structure and one for Perception of Intuitional leadership. The dimensions are perception towards Organizational climate, Human resource, infrastructure and leadership as indicated in the tables below. Besides, the instrument used to asses perception of health worker towards institutional structure and leadership had a good internal consistency with a Cronbach's of alpha $=0.927$ and 0.906 respectively.

\subsection{Perception of Organizational Climate}

About $46.1 \%$ of the respondents agreed and strongly agreed that their hospitals were "a pleasant place to work" (mean $=3.03, \mathrm{SD}=1.137$ ). More than $61 \%$ of the respondents perceived that as their hospitals did not value contribution of its employees. $40.7 \%$ of the respondents perceived that their hospitals would give enough emphasis to the quality of service it provides (mean $=3.029, \mathrm{SD}=1.17$ ). About $69 \%$ of the respondents perceived that their hospitals didn't pay competitive salary. About $67 \%$ of the respondents perceived that their hospitals didn't give an equal opportunity to employees $($ mean $=2.70, \mathrm{SD}=1.30)$ (Table 2$)$.

Table 2. Health worker perception of organizational climate of Chiro and Gelemso Hospitals, East Ethiopia, 2012.

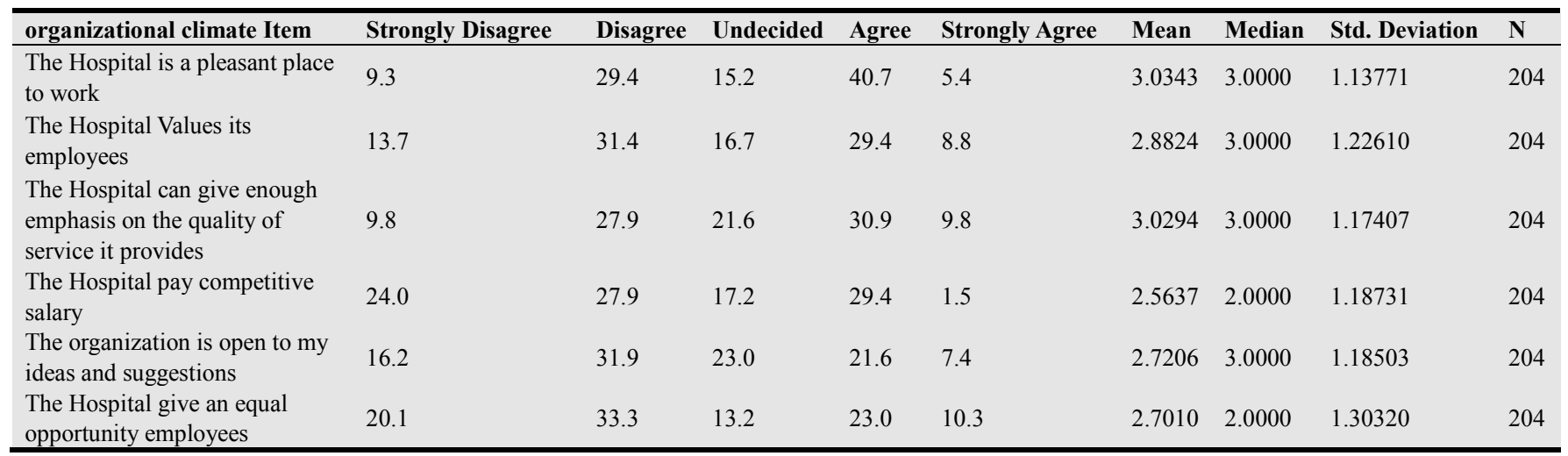

\subsection{Perception of Infrastructure}

About $58 \%$ of the respondents perceived that their hospitals had "needed technological resources for health sector reform" (mean=3.28, $\mathrm{SD}=1.12$ ). Sixty five percent of the respondents perceived that their hospitals did not manage its technological resource effectively (mean=2.96, $\mathrm{SD}=1.13$ ) (Table 3).

Table 3. Health worker perception of Infrastructure of Chiro and Gelemso Hospitals, East, Ethiopia, 2012.

\begin{tabular}{|c|c|c|c|c|c|c|c|c|c|}
\hline Infrastructure Item & Strongly Disagree & Disagree & Undecided & Agree & Strongly Agree & Mean & Median & Std. Deviation & $\mathbf{N}$ \\
\hline $\begin{array}{l}\text { The institution has needed } \\
\text { technological resources for } \\
\text { health sector reform }\end{array}$ & 7.4 & 23.0 & 11.3 & 50.5 & 7.8 & 3.2843 & 4.0000 & 1.12629 & 204 \\
\hline $\begin{array}{l}\text { The Hospital manage its } \\
\text { technological resource } \\
\text { effectively }\end{array}$ & 9.8 & 27.5 & 27.9 & 26.0 & 8.8 & 2.9657 & 3.0000 & 1.13337 & 204 \\
\hline $\begin{array}{l}\text { Adequate facilities and } \\
\text { equipment are available to } \\
\text { support operations for the health } \\
\text { sector reforms }\end{array}$ & 9.3 & 34.8 & 25.5 & 22.5 & 7.8 & 2.8480 & 3.0000 & 1.11481 & 204 \\
\hline $\begin{array}{l}\text { Facilities and equipment well } \\
\text { maintained }\end{array}$ & 11.8 & 33.3 & 33.8 & 18.6 & 2.5 & 2.6667 & 3.0000 & .99093 & 204 \\
\hline
\end{tabular}




\subsection{Perception of Human Resources}

About $60 \%$ of the respondents did not perceive that their hospitals had "adequate staff in all key positions for health sector reform" (mean $=2.86, \mathrm{SD}=1.21$ ). Only $36.3 \%$ of the respondents perceived that "staff are qualified and considered competent" (mean=2.90, $\mathrm{SD}=1.06)$. Sixty four percent of the respondents did not perceive that their hospitals provides opportunities for staff development and training" (mean $=2.81$, $\mathrm{SD}=1.16)($ Table 4).

Table 4. Health worker perception of Human Resource of Chiro and Gelemso Hospitals, East Ethiopia, 2012.

\begin{tabular}{|c|c|c|c|c|c|c|c|c|c|}
\hline Human Resource Item & Strongly Disagree & Disagree & Undecided & Agree & Strongly Agree & Mean & Median & Std. Deviation & $\mathbf{N}$ \\
\hline $\begin{array}{l}\text { The Hospital has adequate staff } \\
\text { in all key position for health } \\
\text { sector reform }\end{array}$ & 15.2 & 29.4 & 15.2 & 33.8 & 6.4 & 2.8676 & 3.0000 & 1.21855 & 204 \\
\hline $\begin{array}{l}\text { Staff are adequate and } \\
\text { considered competent }\end{array}$ & 6.4 & 37.7 & 19.6 & 31.4 & 4.9 & 2.9069 & 3.0000 & 1.06727 & 204 \\
\hline $\begin{array}{l}\text { Compensation is adequate and } \\
\text { for attracting and keeping key } \\
\text { staffs }\end{array}$ & 9.8 & 23.0 & 31.9 & 28.4 & 6.9 & 2.9951 & 3.0000 & 1.08957 & 204 \\
\hline $\begin{array}{l}\text { The Hospital support staff } \\
\text { training and development }\end{array}$ & 14.2 & 30.9 & 18.6 & 31.4 & 4.9 & 2.8186 & 3.0000 & 1.16663 & 204 \\
\hline $\begin{array}{l}\text { The Hospital recruitment and } \\
\text { hiring policy is fair }\end{array}$ & 15.2 & 36.8 & 14.7 & 24.5 & 8.8 & 2.7500 & 2.0000 & 1.23226 & 204 \\
\hline $\begin{array}{l}\text { Staff are held accountable for } \\
\text { getting work done according to } \\
\text { clear performance standard }\end{array}$ & 6.9 & 17.6 & 27.9 & 40.7 & 6.9 & 3.2304 & 3.0000 & 1.04144 & 204 \\
\hline
\end{tabular}

\subsection{Perception of Institutional Leadership}

About $37.8 \%$ of the respondents perceived that their hospital had "leaders that help the organizations to be successful". Two-third of respondents did not perceive that "there is a formal problem solving procedures in the hospital" (mean=2.70, SD=1.17). About $44 \%$ of the respondents disagreed or strongly disagreed that the "the hospital's have clear structure and the decision-making process" (mean $=2.83$, $\mathrm{SD}=1.14)($ Table 5)

Table 5. The perception of health workers towards Leadership of Chiro and Gelemso Hospital, East Ethiopia, 2012.

\begin{tabular}{|c|c|c|c|c|c|c|c|c|c|}
\hline Leadership Item & $\begin{array}{l}\text { Strongly } \\
\text { Disagree }\end{array}$ & Disagree & Undecided & Agree & $\begin{array}{l}\text { Strongly } \\
\text { Agree }\end{array}$ & Mean & Median & $\begin{array}{l}\text { Std. } \\
\text { Deviation }\end{array}$ & $\mathbf{N}$ \\
\hline $\begin{array}{l}\text { We have the leaders that the organization } \\
\text { need to be successful }\end{array}$ & 15.7 & 24.0 & 22.5 & 30.9 & 6.9 & 2.8922 & 3.0000 & 1.20268 & 204 \\
\hline $\begin{array}{l}\text { My supervisor treat all employees in my } \\
\text { work unit equitably }\end{array}$ & 13.2 & 36.8 & 27.0 & 20.1 & 2.9 & 2.6275 & 2.5000 & 1.04029 & 204 \\
\hline $\begin{array}{l}\text { There is a formal problem solving in the } \\
\text { hospital }\end{array}$ & 15.7 & 36.3 & 15.2 & 27.9 & 4.9 & 2.7010 & 2.0000 & 1.17603 & 204 \\
\hline $\begin{array}{l}\text { The governing body are ultimately } \\
\text { accountable for the safety and quality of care, } \\
\text { treatment, and services }\end{array}$ & 12.3 & 30.4 & 25.0 & 28.4 & 3.9 & 2.8137 & 3.0000 & 1.09841 & 204 \\
\hline $\begin{array}{l}\text { The governing body have the knowledge } \\
\text { needed for their roles in the hospital }\end{array}$ & 16.2 & 35.8 & 21.1 & 24.5 & 2.5 & 2.6127 & 2.0000 & 1.09726 & 204 \\
\hline $\begin{array}{l}\text { The hospital's have clear structure and } \\
\text { decision-making process }\end{array}$ & 11.8 & 31.9 & 25.0 & 23.5 & 7.8 & 2.8382 & 3.0000 & 1.14827 & 204 \\
\hline The hospital provides the resources needed & 10.8 & 27.0 & 25.0 & 32.4 & 4.9 & 2.9363 & 3.0000 & 1.10568 & 204 \\
\hline
\end{tabular}

\subsection{Factors That Affect Perception of Health Workers Towards Institutional Structure and Leadership}

Since, the distribution residual is normal as shown in the
Histogram and P-P plot, the relationship between outcome and explanatory variable is linear and observations are Independent, multiple linear regression were applied. 
Histogram

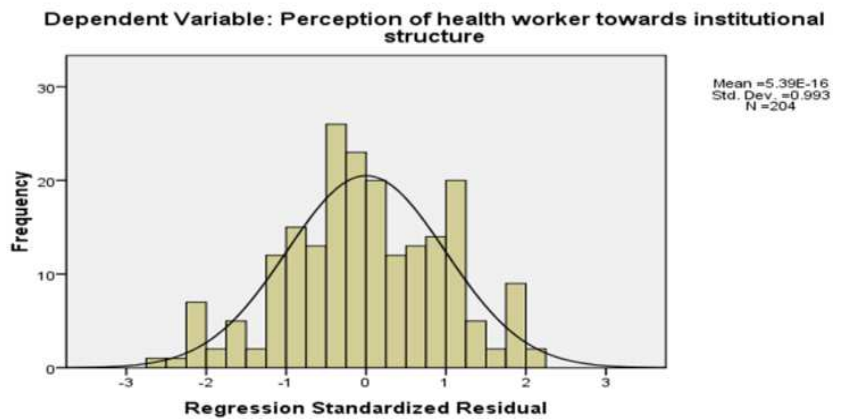

Figure 1. A Histogram that show the distribution dependent variable against the predictors.

Among independent variable, variable Educational status and Position of health worker became the independent predictors for the perception of health workers towards institutional structure with a $\mathrm{P}$ value of $<0.001$ and 0.028 and $95 \%$ CI for $\mathrm{B}$ of $(5.534,17.046)$ and $(-11.291,-.641)$
Normal P-P Plot of Regression Standardized Residual

Dependent Variable: Perception of health worker towards institutional
structure

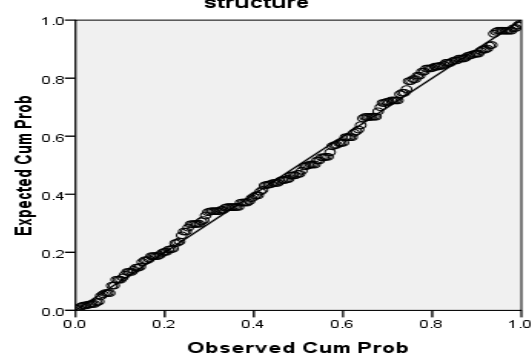

Figure 2. A P-P that show the distribution dependent variable against the predictors.

respectively. (Table6) While place of work was only predictor variable for the perception of health workers towards institutional leadership with a $\mathrm{p}$ value of 0.03 . (Table6)

Table 6. Predictors of health workers perception towards institutional structure, East Ethiopia, 2012.

\begin{tabular}{|c|c|c|c|c|c|}
\hline Explanatory Variables & No. (\%) & p-value & Unstandardized B coefficient & Standardized B coefficient & $95 \%$ CI for B \\
\hline \multicolumn{6}{|l|}{ Sex } \\
\hline Male* & $103(50.5)$ & & & & \\
\hline Female & $101(49.5)$ & 0.933 & -.164 & -.006 & $(-4.034,3.706)$ \\
\hline Single* & $109(53.4)$ & & & & \\
\hline Married & $95(46.6)$ & 0.055 & 3.836 & .144 & $(-.091,7.763)$ \\
\hline Age & & 0.595 & -.170 & -.079 & $(-.801, .460)$ \\
\hline \multicolumn{6}{|l|}{ Educational Status } \\
\hline Level IV/Diploma* & $129(63.2)$ & & & & \\
\hline BSC/Master & $75(36.8)$ & $<0.001$ & 11.290 & .409 & $(5.534,17.046)$ \\
\hline \multicolumn{6}{|l|}{ Position } \\
\hline Non Managerial* & $177(86.8)$ & & & & \\
\hline Managerial & $27(13.2)$ & 0.028 & -5.966 & -.152 & $(-11.291,-.641)$ \\
\hline \multicolumn{6}{|l|}{ Place of work } \\
\hline Gelemso* & $108(52.9)$ & & & & \\
\hline \multicolumn{6}{|l|}{ Income } \\
\hline$<1630 *$ & $102(50)$ & & & & \\
\hline$\geq 1630$ & $102(50)$ & 0.511 & -1.864 & -.070 & $(-7.442,3.714)$ \\
\hline
\end{tabular}

*References category (categories with highest frequency taken as reference categories)

Having BSC/MSC had a 0.409 increment on the perception of health worker towards institutional structure (95\% CI B: 5.534, 17.046) (Table7) and Working at Chiro hospital would increase perception of health workers towards institutional leadership by 0.159 unit with $(95 \%$ CI B: .229 , 4.590). (Table 7)

Table 7. Predictors of health workers perception towards institutional Leadership, East Ethiopia, 2012.

\begin{tabular}{|c|c|c|c|c|c|}
\hline Explanatory Variables & No. $(\%)$ & p-value & Unstandardized B coefficient & Standardized B coefficient & $95 \%$ CI for $B$ \\
\hline \multicolumn{6}{|l|}{ Sex } \\
\hline Male* & $103(50.5)$ & & & & \\
\hline Female & $101(49.5)$ & .207 & -1.497 & -.099 & $(-3.827,0.834)$ \\
\hline \multicolumn{6}{|l|}{ Marital Status } \\
\hline Unmarried* & $109(53.4)$ & & & & \\
\hline Married & $95(46.6)$ & .624 & -.589 & -.039 & $(-2.954,1.776)$ \\
\hline Age & & .336 & -.186 & -.150 & $(-.565, .194)$ \\
\hline \multicolumn{6}{|l|}{ Educational Status } \\
\hline Level IV/Diploma* & $129(63.2)$ & & & & \\
\hline BSC/Master & $75(36.8)$ & .107 & -2.843 & -.181 & $(-6.309, .623)$ \\
\hline \multicolumn{6}{|l|}{ Position } \\
\hline Staff* & $177(86.8)$ & & & & \\
\hline
\end{tabular}




\begin{tabular}{|c|c|c|c|c|c|}
\hline Explanatory Variables & No. (\%) & p-value & Unstandardized B coefficient & Standardized B coefficient & $95 \%$ CI for B \\
\hline Head & $27(13.2)$ & .062 & -3.050 & -.136 & $(-6.257, .156)$ \\
\hline $\begin{array}{l}\text { Place of work } \\
\text { Gelemso* }\end{array}$ & $108(52.9)$ & & & & \\
\hline $\begin{array}{l}\text { Chiro } \\
\text { Income }\end{array}$ & $96(47.1)$ & .030 & 2.410 & .159 & $(.229,4.590)$ \\
\hline$<1630^{*}$ & $102(50)$ & & & & \\
\hline$\geq 1630$ & $102(50)$ & .726 & .597 & .039 & $(-2.762,3.955)$ \\
\hline
\end{tabular}

*References category (categories with highest frequency taken as reference categories

\section{Discussion}

\subsection{Perception of Health Workers Towards Institutional Structure and Leadership}

This study identified the perception of health worker towards their institutional structure and leadership and factor that are associated with it. The overall perception of institutional structure and leadership in this study were $37.2 \%$ and $31.6 \%$ respectively. Out the three dimensions used to measure perception towards institutional structure, perception to human resource have the highest perception which accounts $38.67 \%$ while perception to organizational climate and infrastructure accounts $36.36 \%$ and $36.12 \%$ respectively. This perception of health workers towards their institutional structure was very much lower than the situation in Nigeria which accounts $52.2 \%(1)$.

\subsection{Perception of Organizational Climate}

The overall perception of Organizational Climate was $36.36 \%$. About $59 \%$ of the respondents perceived that as their Hospital did not give enough emphasis on the quality of service it provides. About $69.1 \%$ of the respondents perceived that as their hospital did not pay competitive salary for its employees. In the study by Agyepong and others in Ghana, in January 2002, 94\% out of 551 healthcare workers and $95 \%$ out of 614 in August 2003 mentioned low salary as a workplace obstacle affecting staff performance (9).

This finding is quite similar with countries like Nigeria and Ghana. In Ghana, one of the most significant complaints pointed out by most categories of health professionals were lack of competitive salary, which makes them very dissatisfied and enable them to develop unfavorable perception towards institutional structure $(1,16)$.

\subsection{Perception of Infrastructure}

A total perception of towards infrastructure was $36.12 \%$ and majority of the health workers $(69.6 \%)$ perceived that there were inadequate facilities and equipment in their hospitals and a very high proportion $(78.9 \%)$ perceived that the available facilities and equipment were poorly maintained This finding is quietly similar with case of Nigeria where majority of the healthcare workers $(69.9 \%)$ perceived as there were inadequate facilities and equipment in their hospitals and a similar proportion $(69.4 \%)$ perceived that the available facilities and equipment were poorly maintained (4). Our finding also comparable with the study of Ghana by which $75 \%$ of health workers mentioned lack of essential equipment, tools and supplies as a workplace issue affecting staff performance (9). The rather low perception of health workers may be a reflection of the poor state of the infrastructure available to deliver health care services in Chiro and Gelemso.

\subsection{Perception of Human Resource}

The overall perception of towards Human Resource was about 39\%. Amongst the items that make up the human resources dimension, $59.8 \%$ of the respondents perceived that their hospitals did not have adequate staff in all key positions. This is similar to the report from a study of 614 health care workers in Ghana in August 2003. Agyepong et al reported that $63 \%$ mentioned inadequate staffing as a workplace obstacle affecting staff performance and Nigeria which was also revealed $71.1 \%$ of the respondents perceived that their hospitals did not have adequate staff in all key positions $(1,16)$. Another $74 \%$ of the respondents in this study also perceived as poor compensation had an issue that hinder the recruitment and retention of staff and a similar finding was obtained from the study conducted in Nigeria where $73.4 \%$ of health care workers perceived as poor compensation as an issue hindering the recruitment and retention of $\operatorname{staff}(1)$.

\subsection{Perception of Leadership}

The overall Perception of health workers towards institutional leadership in this study was $31.6 \%$, only $32.8 \%$ of the respondents perceived that there is a formal problem solving in the hospital. Only $27 \%$ (mean=2.61, SD=1.09) of the respondent had perceived that the governing body have adequate knowledge needed for their roles in the hospitals. And it was also revealed that the health workers perception regarding mangers leadership capability was very poor, these might be due to knowledge deficit on effective health system management. Additional to this lack a shared plan had also been a major problem in this study which accounts about $69.1 \%$. at large greater proportion of health workers $(68.7 \%)$ did not perceive that the hospitals have a clear structure and decision-making process this finding was much lesser $\mathrm{t}$ from a study of Nigeria that revealed only $33.6 \%$ of the respondents perceived that the span of control and supervision was not reasonable (1).

\subsection{Factors That Affects Perception of Health Professionals Towards Institutional Structure and Leadership}

Variables Position and Educational status were independent predictors for the perception of health workers towards institutional structure this might be due to the 
general fact that when levels of education of an individual increases, the number of supervisor will decreases whereas benefit package expands. and Place of work (Hospital) was an independent explanatory variable for the perception of health workers towards institutional leadership this might be due to the geographical and infrastructure difference of the two hospital dwelling, Chiro hospital resides in Chiro town, the administrative city of West Haraghe Zone that gives a great advantage in the infrastructure advancement compared with Gelemso Hospital found in Gelemso Town.

\section{Conclusion and Recommendations}

From this study we claim that perception of health worker towards their institutional structure is poor. Likewise, perception of health worker towards institutional leadership is not good enough because of the majority of health care workers from both hospitals perceived their hospital problem solving and decision-making process was unsatisfactory.

From this we recommend, for the mangers to promote health workers primarily based on their performance and formally provide the role and responsibilities of health workers in order to make staffs accountable for the thing they did it. Beside The management has to create equal opportunity to their employees on staff training and development. Above all government and management of hospitals have to do a lot to strength and equip hospitals infrastructure.

\section{Competing Interest}

We warrant that this article is original, does not infringe on any copyright or other proprietary right of any third party, is not under consideration by another journal and has not been previously published.

\section{Acknowledgments}

We are most grateful to staffs and Managers of Chiro and Gelemso Hospitals and Administrators of West Hararghe Zonal Health department for their magnificent cooperation.

\section{References}

[1] Abiodun O., Morenike F., Tinu Olukoga, Geoff H. And Eyitope O.: Healthcare Workers' Perceptions Of Hospitals' Institutional Structure: American Journal Of Tropical Medicine \& Public Health, 2011, 1(3): 79-88.

[2] Beaglehole R, Dal Poz M: Commentary: Public Health Workforce: Challenges And Policy Issues. Human Resources for Health 2004, 1(1):4.
[3] Franco LM, Bennett S, Kanfer R: Health Sector Reform And Public Sector Health Worker Motivation: A Conceptual F\} \{“" ramework. Social Science \& Medicine 2002, 54:1255-1266.

[4] Woodward C: Strategies For Assisting Health Workers To Modify And Improve Skills: Developing Quality Health Care - A Process of Change. In Issues In Health Service Delivery Geneva: World Health Organization; 2000.

[5] Friederike Paul. Health Worker Motivation And The Role Of Performance Based Finance Systems In Africa: Working Paper Series 2009, No.08-96: 1.

[6] World Bank: World Development Report 2004: Making Services Work for Poor People. Washington, DC 2003.

[7] Kari Hartwig, Et Al.: Hospital Management In The Context Of Health Sector Reform: A Planning Model In Ethiopia, International Journal Of Health Planning And Management, 2008; 23: 203.

[8] Joint Learning Initiative (JLI): Human Resources For Health: Overcoming the Crisis Cambridge, MA: Harvard University Press; 2004.

[9] Agyepong, I.A., Anafi, P., Asiamah, E., Ansah, E.K., Ashon, D.A., Narh-Dometey, C.: Health Worker (Internal Customer) Satisfaction and Motivation in the Public Sector in Ghana; International Journal Of Health Planning And Management, 2004, 19(4): 319-36.

[10] Anuar, Zahedi F., Kadir A, Mokhtar Ab.: Occupational Safety And Health Risk Perception Among Medical Laboratory Workers In Klang Valley: Journal Of Community Health 2009: Vol 15 Number 2.

[11] Paul M. Schyve: Leadership in healthcare organizations, A GUIDE TO JOINT COMMISSION LEADERSHIP STANDARDS, 2009.

[12] World Health Organization: Migration Of Health Professionals In Six Countries: A Synthesis Report Brazzaville: World Health Organization Regional Office for Africa; 2003.

[13] Mcintyre, R. M., Bartle, S., Landis, D. \& M. Dansby: The Effects of Equal Opportunity, Fairness Attitudes on Job Satisfaction, Organizational Commitment, and Perceived Work Group Efficacy.” Military Psychologym 2002 14: 299.

[14] Rebecca L. Servant Leadership: A Model For Organizations Desiring A Workplace Spirituality Culture: Business \& Technology Bulletin, 2008, 12(4):14.

[15] Rowe AK, De Savigny D, Lanata CF, Victora CG: How Can We Achieve And Maintain High-Quality Performance Of Health Workers In Low-Resource Settings? The Lancet 2005, 366:1026-1035.

[16] Sakyi, E.K. (2008). A retrospective content analysis of studies on factors constraining the implementation of health sector reform in Ghana. International Journal of Health Planning and Management, 23(3), 259-285. 